\title{
Colonoscopic polypectomy in children
}

\author{
J R DOUGLAS, C A CAMPBELL, D M SALISBURY, J A WALKER-SMITH, C B WILLIAMS
}

\section{Summary and conclusions}

Five children presenting with chronic and intermittent rectal bleeding were diagnosed as having colorectal polyps by fibreoptic colonoscopy performed under sedation. Three of the children had had barium-enema films reported on as normal. Eight polyps were seen, of which six were proximal to the sigmoid colon. All were removed endoscopically (one by proctoscopy, one by snare-intussusception) without complication.

Colonoscopic polypectomy is a safe and efficient procedure in children, and colonoscopy may be regarded as first-line management in those with rectal bleeding.

\section{Introduction}

In children chronic or intermittent bleeding from the rectum is a relatively uncommon yet alarming event in which colorectal polyps must be considered. Fibreoptic colonoscopy and colonoscopic polypectomy are well established in adults, ${ }^{1}$ and the introduction of these procedures in childhood ${ }^{3}$ now permits a similarly safe, effective method of investigating the entire colon, with the possibility of immediate, definitive treatment when polyps are seen..$^{5}$

We describe the colonoscopic diagnosis of colorectal polyps in five children and the different endoscopic methods of their removal.

\section{Patients and methods}

During January 1977 to July 198074 children aged 2-16 years were examined by colonoscopy on 80 occasions. The examinations were performed for suspected chronic inflammatory bowel disease or undiagnosed rectal bleeding. In five of these children colorectal polyps were seen.

Preparing the bowel for colonoscopy entailed restricting diet to clear fluid for 24 hours; giving a senna syrup aperient (X-Prep $1 \mathrm{ml} / \mathrm{kg}$ ) on the afternoon before examination; and continuing a saline enema until the return was clear, followed by an oxyphenisatin (Veripaque) enema on the morning of the examination. All procedures were conducted under sedation. Premedication with droperidol 0.2-0.6 $\mathrm{mg} / \mathrm{kg}$ by mouth one hour before, then pethidine $1-2 \mathrm{mg} / \mathrm{kg}$ and diazepam $0 \cdot 2-0 \cdot 4 \mathrm{mg} / \mathrm{kg}$ intravenously at the time of examination was satisfactory. A 23-gauge intravenous needle (Abbott butterfly) was left in situ for further sedation if required and the administration of naloxone $0.01 \mathrm{mg} / \mathrm{kg}$ on completion. Blood was cross-matched and available before polypectomy.

Either an adult colonoscope or a prototype paediatric colonoscope was used depending on the age and size of the child. At the time of colonoscopy some children had minor abdominal discomfort during looping of the instrument or air insufflation. The combination of pethidine and diazepam gave satisfactory analgesia with subsequent amnesia for the procedure.

Department of Child Health, St Bartholomew's Hospital, London EC1A 7BE

J R DOUGLAS, MRCP, CICRA research fellow

C A CAMPBELL, MRCP, research fellow

D M SALISBURY, MRCP, senior registrar

J A WALKER-SMITH, MD, FRCP, reader in paediatric gastroenterology

C B WILLIAMS, FRCP, consultant physician
All polyps seen were removed either by snare polypectomy or by intussusception to the anus at colonoscopy (see below) or, as in $a \propto$ case of rectal polyp, by electrocoagulation of the stalk through aw proctoscope. All the polyps were examined histologically.

The children were observed closely after the procedure for any. sign of abdominal pain or rectal bleeding. Haemoglobin concentration was measured 48 hours after polypectomy and at subsequent out- $\omega$ patient review.

\section{Results}

The clinical presentation was with chronic and intermittent rectal bleeding associated with abdominal pain in three children and $\vec{\omega}$ without pain in two. Two children, aged 2 years 2 months and 2 years $\infty$ 10 months, had had sufficient rectal bleeding over 11 months and 6 months respectively to render them anaemic at presentation (see table), and one had finally presented when the polyp had prolapsed $N$ through the rectum.

Bowel preparation was satisfactory in all cases. Eight polyps were? seen, one in the rectum $5 \mathrm{~cm}$ from the anal verge, one in the sigmoid $\Phi$ colon, and six proximal to the rectum and sigmoid colon. The colon was otherwise normal in all instances.

The polyps proximal to the sigmoid colon were removed by snarepolypectomy at the initial examination. All had narrow pedicles and $\mathscr{\odot}$ presented no technical difficulty despite their apparently large. diameter (table). The rectal polyp (case 4) was more easily removedO

Ages, haemoglobin concentrations, and diameters of eight polyps seen in five ํํำ children

\begin{tabular}{ccccc}
\hline Case No & $\begin{array}{c}\text { Age } \\
\text { (years, months) }\end{array}$ & $\begin{array}{c}\text { Haemoglobin } \\
(\mathbf{g} / \mathrm{dl})\end{array}$ & $\begin{array}{c}\text { Polyp diameter } \\
(\mathrm{cm})\end{array}$ \\
\hline 1 & 2,2 & $9 \cdot 1$ & $3,2,1$ \\
2 & 2,10 & $6 \cdot 5$ & 3 \\
3 & 49 & $12 \cdot 7$ & 2,1 \\
4 & 12 & $13 \cdot 4$ & 0.9 & 10.0 \\
5 & 12 & & & \\
\hline
\end{tabular}

through a proctoscope, as it was only $5 \mathrm{~cm}$ from the anal verge. In the case of the child with prolapse of a polyp through the rectum (case 2) the polyp was seen at initial colonoscopy at the junction of the proximal sigmoid and descending colon. It had a diameter of $N$ $3 \mathrm{~cm}$ and an apparently broad stalk and was thought likely to bleed $D$ with conventional snare transection. It was later snared at colonoscopy under a brief general anaesthetic and drawn through the rectum to be ligated and excised externally (figure).

There were no complications during or after either the colonoscopic $\mathrm{N}$ examinations or colonoscopic polypectomies. Four of the children had juvenile polyps, and the fifth, with ulcerative colitis, had an inflammatory polyp. The juvenile polyps were typical histologically, one showing some ossecus tissue, which is occasionally found in such hamartomas.

\section{Discussion}

Though colorectal polyps are rare in children, they are an important cause of chronic and intermittent blood loss through 8 the rectum. This is not usually enough to cause iron-deficiencys anaemia, ${ }^{6}$ though the two youngest children in this group wereco․ anaemic, one with a haemoglobin concentration of $6.5 \mathrm{~g} / \mathrm{dl}$.

Most polyps in children are hamartomas, and $70-80 \%$ of these reportedly occur in the rectum or sigmoid colon. ${ }^{7}$ In these sites diagnosis is possible by rectal digital examination 


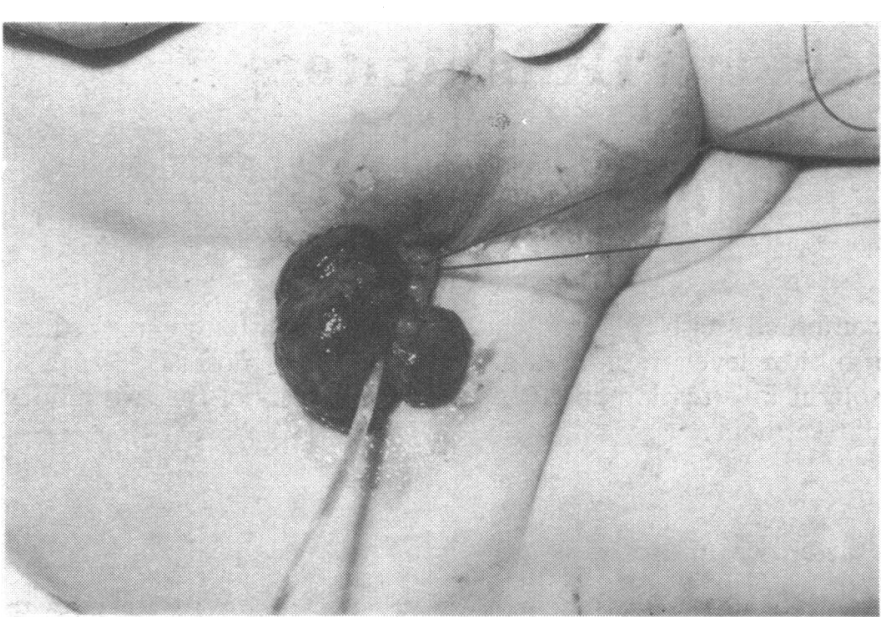

Case 2. Polyp with long, slender stalk snared when prolapsed per rectum to be ligated and excised externally.

or sigmoidoscopy. Polyps lying more proximally in the colon or multiple polyps ${ }^{7}$ may present difficulties in diagnosis and management. Six of the eight in this group were proximal to the sigmoid, and two children had multiple polyps.

Fibreoptic colonoscopy under sedation performed by a skilled endoscopist is now our initial means of investigating children with undiagnosed rectal bleeding. The procedure permits safe and effective inspection of the entire colon to exclude multiple polyps and is usually completed within 20 minutes, when the child can return to a normal ward routine. If this procedure is not available, air-contrast barium enema would be the radiological investigation preferred. Standard barium-enema studies have an unsatisfactorily low diagnostic yield and may be difficult in young children. Two of the children in this group had had normal barium-enema films, and in another child the study had failed as he was uncooperative.

When polyps are seen at colonoscopy immediate polypectomy is possible with the existing sedation. When the polyp lies in or distal to the proximal sigmoid it may be snared at colonoscopy and prolapsed through the rectum for external removal. ${ }^{8}$ Polypectomy before the advent of snare polypectomy required laparotomy and colotomy under general anaesthesia. In addition to the extended stay in hospital laparotomy and colotomy may be complicated by wound dehiscence, intestinal obstruction, fistulae, and subsequent adhesions. ${ }^{7}$ Some centres therefore advocate conservative management, as juvenile polyps have no premalignant potential and may avulse spontaneously. As colonoscopic polypectomy is a safe, effective treatment undertaken at the time of investigation and cancels the morbidity and concern of rectal bleeding, it is our preferred management for symptomatic polyps.

Both colonoscopy and polypectomy do, however, have small inherent risks of complication. Colonoscopy may be complicated by perforation ${ }^{9}$ or subsequent bleeding, ${ }^{10}$ with either immediate or delayed haemorrhage. ${ }^{11}$ Perforation of the bowel at the time of or as a delayed sequel to polypectomy sometimes occurs in children. ${ }^{2}$ This rarely occurs in adults and may reflect the relative thinness of the bowel wall in children.

After proper bowel preparation fibreoptic colonoscopy under sedation is a safe and very effective method of investigating the entire colon in children. The availability of polypectomy on the same occasion avoids the morbidity associated with an abdominal operation. To maintain the current high standard of safety for these procedures, and in particular for colonoscopic polypectomy, this technique should be confined to skilled endoscopists with a knowledge of paediatric gastrointestinal disease.

We thank Crohn's in Childhood Research Appeal (CICRA) for financial support, and the nursing staff in Lucas ward, $S$ Bartholomew's Hospital.

\section{References}

1 Swarbrick ET, Fevre DI, Hunt RH, Thomas BM, Williams CB Colonoscopy for unexplained rectal bleeding. Br Med $₹$ 1978;ii:1685-7.

${ }^{2}$ Holgersen LO, Mossberg SM, Miller RE. Colonoscopy for rectal bleeding in children. $\mathcal{F}$ Pediatr Surg 1978;13:83-5.

${ }^{3}$ Cremer M, Pecters JP, Emonts P, Rodesch P, Cadranel S. Fibroendoscopy of the gastrointestinal tract in children-experience with newly designed fibrescopes. Endoscopy $1974 ; 6$ :186-9.

${ }^{4}$ Gleason WA, Goldstein PD, Schatz BA, Tedesco FJ. Colonoscopic removal of juvenile colonic polyps. $\mathcal{F}$ Pediatr Surg 1975;10:519-21.

5 Liebman WM. Fiberoptic endoscopy of the gastrointestinal tract in infants and children. Fiberoptic colonoscopy and polypectomy in 15 children. Am $\mathcal{f}$ Gastroenterol 1977;68:452-5.

- Knox WG, Miller RE, Begg CF. Juvenile polyps of the colon. Surgery $1960 ; 48: 201-9$.

7 Holgersen LO, Miller RE, Zintel HA. Juvenile polyps of the colon. Surgery $1971 ; 69: 288-93$.

${ }^{8}$ Gillespie PE, Nicholls RJ, Thomson JPS, Williams CB. Snare polypectomy by sigmoid-rectal intussusception. Br Med $\mathcal{F}$ 1978;i:1395-6.

Smith LE. Complications of colonoscopy and polypectomy. Dis Colon Rectum 1976;19:407-12.

10 Livstone EM, Cohen GM, Troncale FJ, Touloukion RJ. Dizstatic serosal lacerations: an unrecognised complication of colonoscopy. Gastroenterology $1974 ; 67: 1245-7$.

11 Cotton PB, Williams CB. Practical gastrointestinal endoscopy. Oxford: Blackwell Scientific, 1980.

(Accepted 30 September 1980)
ONE HUNDRED YEARS AGO The employment of unqualified assistants to manage cheap "dispensaries" is becoming a growing scandal, and is attracting just censure from magistrates. Mr George Collier, deputy coroner for East Middlesex, resumed an inquiry this week at the Fountain, Virginia Road, St Matthew's, respecting the death of Mrs Sarah Newman, aged 56, who resided at No 4, Wellington Row, Bethnal Green. The inquiry had been adjourned for the purpose of obtaining the evidence of $\mathrm{Mr}$ John Smith Crone, who is in charge of the Virginia Provident Dispensary, Hackney Road, and who attended the deceased till the time of her death, which took place on the 3rd instant. He now stated that, when he last visited his patient, he found her in a dying state, and he sent a messenger for Mr Smyth, of No 13, Colebrooke Row, City Road, who was his employer, and the proprietor of the dispensary. Witness sent for Mr Smyth about eight o'clock, and he arrived at about eleven. The woman was then dead. Hereupon, the following conversation ensued.-The Coroner: You say no medical aid could have saved her, but you are assuming you are infallible. You are not a qualified practitioner; and; to make matters worse, you send to the City Road for aid, when the neighbourhood in which the deceased lived is surrounded with medical men. You admit yours is a ready-money business, but it is conducted under false colours. You have no name over your door or upon your labels. The public think they are dealing with qualified men, which is a fallacy. The fact is, $\mathrm{Mr}$ Smyth was not sent for at all; you sought his aid when you saw the dangerous condition of the patient. I hope the publicity given to this case will open the eyes of the public to such reprehensible and irregular practices. A juryman said attention ought to be called to the increased growth of so-called "provident dispensaries," which are supposed to be conducted by properly qualified men, while in reality they were carried on by totally incompetent and irresponsible persons, thereby misleading the public. $\mathrm{He}$ considered $\mathrm{Mr}$ Smyth as much to blame as Mr Crone. Mr Smyth was then called, and said he had made a post mortem examination of the body, and the cause of death was an effusion of serum on the brain, and he considered the deceased had been properly treated for that complaint. Ultimately, the jury returned a verdict in accordance with the medical testimony; and added their opinion that the conduct of Messrs Smyth and Crone was irregular and highly reprehensible. (British Medical fournal, 1880.) 